\title{
Drug eruption by antihistamine mistaken for chronic urticaria in a child
}

\author{
Gun Moo Lee, MD', Shou-Yu Chu, MD², Sung Yeon Kang, MD', Hyo-Bin Kim, MD, PhD², Jin-Sung Park, MD, , Ja Kyoung Kim, MD, PhD ${ }^{1,3}$ \\ ${ }^{1}$ Department of Pediatrics, Kangwon National University Hospital, Chuncheon, ${ }^{2}$ Department of Pediatrics, Inje Unversity Sanggye Paik Hospital, Seoul, ${ }^{3}$ Department \\ of Pediatrics, Kangwon National University School of Medicine, Chuncheon, Korea
}

Although rare, antihistamines can cause adverse effects, including drug-induced eruptions or anaphylaxis. A 4-year-old child visited the pediatric department of a hospital for skin eruptions after administration of antihistamines, (e.g., ucerax [hydroxyzine] or leptizine [levocetirizine]), for cholinergic rashes; he did not have pruritus. Skin prick, intradermal, and drug provocation tests were performed to determine the relationship between the antihistamines and eruptions. Levocetirizine induced wheals in the skin prick test and a rash in the oral drug provocation test. In contrast, ketotifen induced no reaction in the skin prick test but showed a positive reaction in the oral provocation test. Our case report highlights that children can experience the same types of adverse reactions as seen in adults, and cross-reactivity between various antihistamines can occur.

Key words: Histamine antagonists, Drug eruptions, Maculopapular, Chronic urticaria
Corresponding author: Ja Kyoung Kim, MD, PhD Department of Pediatrics, Kangwon National University School of Medicine, 1 Gangwondaehak-gil, Chuncheon 24341, Korea

Tel: +82-33-258-2090

Fax: +82-33-258-2418

E-mail: kjaky@kangwon.ac.kr

https://orcid.org/0000-0001-6724-3400

Received: 6 June, 2018

Revised: 19 July, 2018

Accepted: 8 August, 2018

\section{Introduction}

More than 40 types of antihistamine drugs have been developed, and this group of drugs is extensively used worldwide. ${ }^{1,2)}$ Common adverse effects caused by antihistamines include type A adverse reactions, such as drowsiness, decrease in cognitive-motor function, and mouth dryness, and although rare, type B adverse reactions, such as urticaria, eruption, and anaphylaxis, and are constantly being reported. ${ }^{1,3)}$ However, because second-generation antihistamines are commonly used as the primary treatment choice for urticaria, many physicians tend to overlook the fact that skin eruption with pruritus may be caused and/or exacerbated by antihistamines. In the present case report, we describe a 4-year-old patient with intermittent skin eruption who was diagnosed with chronic urticaria due to exacerbation of rashes after being administered antihistamines. We first report that the child patient was later diagnosed with a skin eruption caused by antihistamines through a drug provocation test and exhibited cross-reactions with various antihistamine drugs.

\section{Case report}

\section{Present illness}

A 4-year-old male patient presented to the hospital with a skin eruption, which had exacerbated on his hands and feet after taking Ucerax (hydroxyzine, Korea UCB Co., Seoul, Korea) or Leptizine (levocetirizine, Han Wha Pharma Co., Chuncheon, Korea) for treating urticaria. The patient had begun to exhibit urticaria resembling small grains with pruritus at the skin folds and torso since 10 months. He was then diagnosed with cholinergic urticaria and administered
Copyright (C) 2019 by The Korean Pediatric Society

This is an open-access article distributed under the terms of the Creative Commons Attribution NonCommercial License (http://creativecommons.org/ licenses/by-nc/4.0/) which permits unrestricted noncommercial use, distribution, and reproduction in any medium, provided the original work is properly cited. 
antihistamine drugs. The patient had repeated episodes of such rashes and was administered antihistamine drugs upon recurrent diagnosis of cholinergic urticaria and chronic urticaria. However, the patient's parents discontinued antihistamine administration as the skin rashes appeared to expand and were prolonged whenever antihistamines were administered, and the rashes would disappear approximately 2 days or more after discontinuing antihistamine administration. The rashes would begin to appear on the hands and feet within an hour or two after drug administration. Although antihistamine administration led to increased pigmentation and number of hives, no severe pruritus was observed.

\section{Past history}

The patient had a history of facial urticaria, which erupted after consuming watermelons, as well as other histories of intermittent facial skin eruptions after consuming cucumbers and bananas, although the symptoms were resolved without any treatment. However, the patient had been eating these foods as there were no skin eruptions upon consumption recently. In addition, the patient had a history of eruption after taking a cold medication.

\section{Physical examination}

When the patient visited the hospital, no visible skin lesion was observed as he had discontinued medication for 2 weeks. In order to verify the cause of skin eruption as well as determine a safer antihistamine drug for the patient, a drug provocation test was performed.

\section{Laboratory test}

Laboratory test performed 2 years ago, when rashes erupted after consuming food, revealed a total white blood cell (WBC) count of

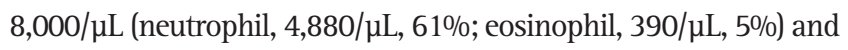
total IgE in plasma of $122.40 \mathrm{IU} / \mathrm{mL}$ (reference value, 1.31-165.3 IU/ $\mathrm{mL}$ ). Allergy blood test results were as follows: watermelon (Unicap RF 329)=1.07 KU/L, Banana (Unicap F92) $=0.67 \mathrm{KU} / \mathrm{L}$, and cucumber (Unicap F244)=1.0 KU/L. At the time of drug induction test, peripheral blood test revealed a WBC count of $6,900 / \mu \mathrm{L}$ (neutrophil,

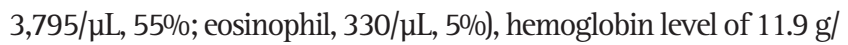
$\mathrm{dL}$, hematocrit of $37.1 \%$, and platelet count of $242,000 / \mu \mathrm{L}$. Total IgE in plasma of $340.7 \mathrm{IU} / \mathrm{mL}$ (reference value, 1.5-158.0 IU/mL).

\section{Progress}

The drugs that were considered in the provocation tests were injectable antihistamines and antihistamine syrups, which are commonly used types of antihistamines, as well as injectable $\mathrm{H}_{2}$ antagonists. The following drugs were selected: injectable antihistamines, including chlorpheniramine maleate $4 \mathrm{mg} / 2 \mathrm{~mL}$ (Peniramin, Yuhan, Seoul, Korea) and ranitidine $\mathrm{HCl} 50 \mathrm{mg} / 2 \mathrm{~mL}$ (Curan, Ildong Pharm, Seoul, Korea), and antihistamine syrups, including levocetirizine HCL 0.5 mg/mL (Serenzal, Samil Pharm, Seoul, Korea), ketotifen fumarate $0.2 \mathrm{mg} / \mathrm{mL}$ (Zaditen, Novartis Korea, Seoul, Korea), loratadine $1 \mathrm{mg} / \mathrm{mL}$ (Clarityne, Bayer Korea, Seoul, Korea), and mequitazine $0.5 \mathrm{mg} / \mathrm{mL}$ (Primalan, Bukwang Pharm, Seoul, Korea). The drug provocation tests included a skin prick test using antihistamine syrups and injectable antihistamines, and then oral provocation tests were performed using drugs that showed a negative result in the skin prick test and levocetirizine, which is a suspected medication considering the patient's medical history. Furthermore, intradermal tests were performed for the injectable $\mathrm{H}_{1}$ antihistamines and $\mathrm{H}_{2}$ antagonists. The skin prick test was performed by placing a single drop of each of the 4 antihistamine syrups, positive control liquid (histamine), and negative control liquid (0.9\% saline) on the upper forearm followed by a skin prick with a disposable lancet. Each allergen sample and control liquid was left for 20 minutes on the skin, after which the size of urticaria and skin eruptions was observed. While ketotifen showed a negative reaction in the skin prick test, all other drugs showed wheal reaction (Table 1). The intradermal test was performed by injecting Peniramin, Curan, and negative control liquid (0.9\% saline) into the surface of skin with a 26-G needle to create $2-\mathrm{mm}$ blisters, and results were noted at 20 minutes after the injections. Both Peniramin and Curan induced wheal with a diameter greater than $2 \mathrm{~mm}$ (Table 1). According to the method used by Kim et al., ${ }^{4)}$ the oral provocation test was performed by administering half of the standard dose and standard dose, after which changes in blood pressure, pulse, and appearance of any other symptoms in a 2-hour period were observed. At 120 minutes after administering 0.5-mg ketotifen, which showed a negative result in the skin prick test, 1 or 2 macula appeared, yet without pruritus. Subsequently, 30 minutes after administering an additional $1 \mathrm{mg}$, the number of macula increased, but the total number appeared to be less than 5 and there were no more changes observed up to 120 minutes. On the other hand, the number and size of macula around

Table 1. Results of the skin prick test, intradermal test, and oral provocation test to confirm a drug-induced rash in this patient

\begin{tabular}{|c|c|c|c|c|}
\hline Classification & $\begin{array}{l}\text { Histamine } \\
\text { antagonist* }\end{array}$ & $\begin{array}{c}\text { Skin prick } \\
\text { test } \\
\text { (wheal, mm) }\end{array}$ & $\begin{array}{l}\text { Intradermal } \\
\text { test } \\
\text { (wheal, mm) }\end{array}$ & $\begin{array}{c}\text { Oral } \\
\text { provocation } \\
\text { test }\end{array}$ \\
\hline 0.9\% Saline & - & $\mathrm{N}$ & $\mathrm{N}$ & ND \\
\hline Histamine & - & $5 \times 5$ & ND & ND \\
\hline Alkylamine & Chlorpheniramine & $3 \times 3$ & $6 \times 6$ & ND \\
\hline Piperazine & Levocetirizine $^{\dagger}$ & $2 \times 2$ & ND & + \\
\hline \multirow[t]{2}{*}{ Piperadine } & Ketotifen ${ }^{\ddagger}$ & $\mathrm{N}$ & ND & + \\
\hline & Loratadine & $4 \times 4$ & ND & ND \\
\hline Phenothiazine & Mequitazine & $2 \times 2$ & ND & ND \\
\hline $\mathrm{H}_{2}$ blocker & Ranitidine & $3 \times 4$ & $8 \times 7$ & ND \\
\hline
\end{tabular}

$\mathrm{N}$, negative reaction; +, positive reaction; ND, not done.

*Levocetirizine, ketotifen, loratadine, and mequitazine are syrups, and chlorpheniramine and ranitidine were administered through injection. ${ }^{\dagger}$ Levocetirizine is an antihistamine that caused a drug-induced skin eruption according to the patient's previous history. ${ }^{\ddagger}$ Ketotifen is the only antihistamine drug that did not induce urticaria in the skin prick test. 
the wrist and ankle gradually increased during the 30-minute to 120-minute period after the administration of levocetirizine 1.2 $\mathrm{mg}$ (2.5 mL) (Fig. 1). According to the test result, the patient was diagnosed with drug-induced skin eruption caused by levocetirizine and was advised to avoid taking similar antihistamine agents and agents that affect the $\mathrm{H}_{2}$ receptor, such as Curan, as cross-reactions caused by these agents can cause similar skin eruptions.

This study was approved by the Institutional Review Board of Kangwon National University Hospital (KNUH-2018-09-005). As a retrospective case report, written consent was waived.

\section{Discussion}

Antihistamines have been used in the clinical setting for over 70 years since the first-generation antihistamines were introduced in the 1940s. ${ }^{5)}$ More than 45 antihistamines are available for use worldwide, and these antihistamine agents alter allergic reactions by affecting histamine receptors. ${ }^{5}$ Histamines are synthesized from histidine, an amino acid, by L-histidine decarboxylase and can cause various reactions through 4 different types of histamine receptors. Antihistamines that are commonly administered for allergic diseases alter immune reaction by affecting the $\mathrm{H}_{1}$ receptor. $\mathrm{H}_{1}$ antihistamines are classified into 6 different groups depending on the chemical structure of each molecule: alkylamines that include chloropeniramine; piperazines that include hydroxyzine and cetirizine; piperidines that include ketotifen, loratadine, and fexofenadine; ethanolamines that include dimenhydrinate, which is commonly used for nausea, emesis, and dizziness; ethylendiamines, although no medications in this group are currently used in Korea; and phenothiazines that include mequitazine. In addition, these antihistamines are further divided into first- and second-generation antihistamines depending on the permeability of the blood-brain barrier. ${ }^{5,6)}$ As for the antihistamines that caused skin eruption in our patient, hydroxyzine and levocetirizine, although they may differ in terms of functionality, both belong to the piperazine group in terms of chemical structure. Therefore, these 2 medications most likely caused skin eruption based on the same mechanism, considering the medical history of the patient.

Common adverse drug reactions caused by $\mathrm{H}_{1}$-antihistamines are drowsiness and diminished mental and motor function caused by inhibition of histamine receptors in the central nervous system or symptoms such as pupil dilation, dry mouth, dry eyes, constipation, and urinary retention and hesitancy caused by inhibition of muscarinic receptors. Additionally, the antiserotonin effect of antihistamines may cause increase in appetite and weight, and alpha-adrenergic inhibition can cause dizziness and symptoms of orthostatic hypotension. ${ }^{5)}$ Other than these expected adverse reactions, side effects, such as drug-induced skin eruption and anaphylaxis caused by immediate hypersensitivity, which belong to type B adverse reactions, are consistently reported., ${ }^{3,7)}$

The drug-induced skin eruption observed in our patient is one of the most common drug adverse reactions on the skin, and it is characterized by a sudden onset and symmetric, wide distribution of the lesions. ${ }^{7,8)}$ Studies report that among antihistamines, hydroxyzine of the piperazine group causes the most number of unspecified skin eruptions. ${ }^{7)}$ Moreover, many cases of urticaria and fixed drug eruptions are being reported; in this case, cetirizine is the most common cause. ${ }^{7)}$ Although cross-reactions with these antihistamines that cause such rashes are not clearly elucidated, some studies have reported that antihistamines similar in chemical structure, despite the functional difference, may cause a cross-reaction with the same

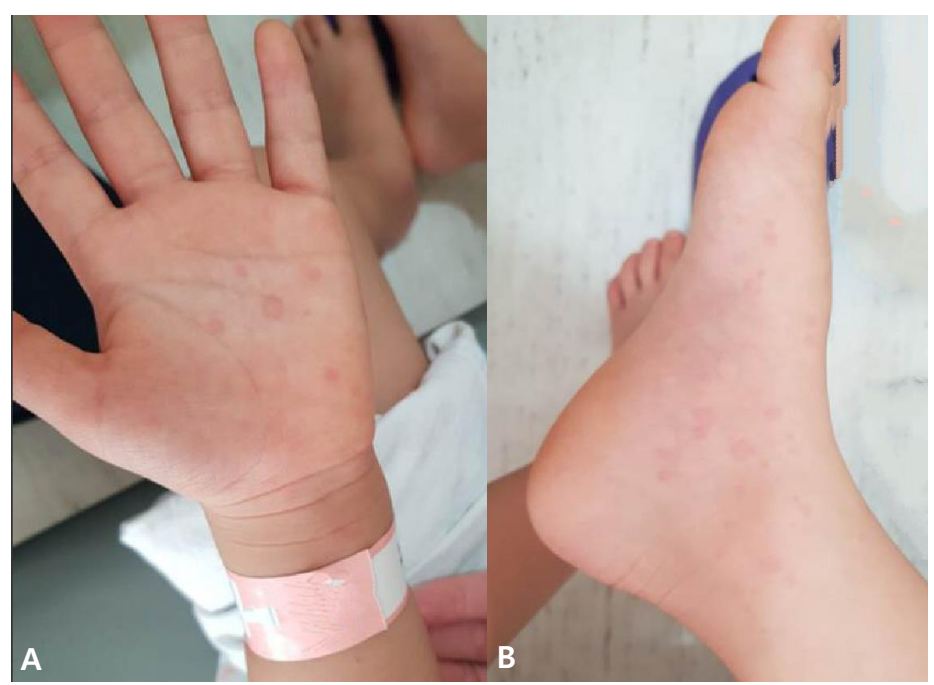

Fig. 1. Skin lesions caused by an antihistamine provocation test. Macular eruptions appeared on the hand (A) and foot (B) 30 minutes after administration of 2.5-mg levocetirizine. 
symptoms. ${ }^{1,9,10)}$ In particular, Kim and Lee ${ }^{1)}$ reported an adult patient with urticaria caused by antihistamine showing cross-reactions with many types of antihistamines and $\mathrm{H} 2$ receptor antagonists. According to this study, we had planned a skin prick test, intradermal test, and oral provocation test for our patient. As a result, our patient also showed a positive reaction with all antihistamines used in the test as well as ranitidine, an $\mathrm{H}_{2}$ receptor antagonist, indicating a possibility of cross-reaction (Table 1). The findings of our case verify a few facts: first, the presence of wheal reaction itself is more important than comparing the size of the allergen wheal with that of the positive control group using histamine when interpreting the result of skin prick test. While previous studies conducted the skin test according to varying standards set by the researchers of each study, the presence of wheal was largely reported as a sign of positive reaction in many cases. ${ }^{9-11)}$ Second, although a certain antihistamine drug shows a negative skin test result, it cannot be used as an alternative treatment option if other antihistamines with the same chemical structure induced hives. As for our patient, the oral provocative test result of ketotifen, which showed a negative result in the skin test, induced a skin eruption at 120 minutes after administration, and the number of skin eruptions increased as the dose increased, although it was a small number. Ketotifen has the same chemical structure as loratadine; while our patient showed a negative skin reaction with ketotifen, the size of wheal was the greatest with loratadine (Table 1). This result suggests that crossreactions can occur with antihistamines with different chemical structures as well as those with the same chemical structure.

The mechanism of skin eruption or anaphylaxis due to antihistamine is not yet completely known. Shakouri and Bahna ${ }^{7)}$ reported that many patients with a positive oral drug provocative test also showed a negative result for the skin test. This result suggests that drug-induced skin eruption is largely caused by a mechanism other than an IgE-mediated mechanism, and a drug provocation test is necessary to confirm a diagnosis. The results of skin prick test, intradermal test, and oral provocation test proved that our patient had a drug-induced skin eruption caused by antihistamines. Kim and Lee ${ }^{1)}$ state that one may consider sporadic steroid administration when skin eruption occurs in a patient with cross-reaction in various antihistamines and that the use of anti-IgE and desensitization may also be considered if the symptom is severe. However, because using anti-IgE would be difficult considering our patient being only 4 years old, antihistamines were substituted with intranasal local administration of anticholinergic agents for respiratory symptoms such as common cold and scopolamine butylbromide was orally administered for cholinergic skin eruptions. ${ }^{12,13)}$
Although most adverse reactions caused by antihistamines have been reported in adult patients, our report is the first case of a child showing drug adverse reaction against multiple antihistamines. Regardless of the mechanism, unpredictable type B adverse drug reactions may occur due to antihistamines, and it is important that we should give an attention to patient's history in order to notice such adverse reactions. Although antihistamines are important drugs used for treating urticaria or anaphylaxis, we should not forget that antihistamines are not completely safe drugs for use.

\section{Conflicts of interest}

No potential conflict of interest relevant to this article was reported.

\section{References}

1. Kim YU, Lee J. Drug hypersensitivity to various antihistamines with cross-reactions. Allergy Asthma Respir Dis 2014;2:134-7.

2. Simons FE. Advances in H1-antihistamines. N Engl J Med 2004; 351:2203-17.

3. Coattrenec Y, Spoerl D, Jandus P, Harr T. Anaphylactic shock to H1 antihistamine drug bilastine: a case report. J Allergy Clin Immunol Pract 2018;6:256-7.

4. Kim SS, Lee SK, Nahm DH, Park HS. A case of acetaminophen induced bronchial asthma without aspirin sensitivity. J Asthma Allergy Clin Immunol 2000;20:545-50.

5. Simons FE, Simons KJ. Histamine and H1-antihistamines: celebrating a century of progress. J Allergy Clin Immunol 2011;128:1139-50.e4.

6. Choi YS, Park YM, Rha YH, Choi SH. An overview and considerations in prescribing H1-antihistamine. J Korean Med Assoc 2013;56:231-9.

7. Shakouri AA, Bahna SL. Hypersensitivity to antihistamines. Allergy Asthma Proc 2013;34:488-96.

8. Korean Dermatological Association. Textbook of dermatology. 6th ed. Seoul: Medbook Co., 2014.

9. Rodríguez del Río P, González-Gutiérrez ML, Sánchez-López J, Nuñez-Acevedo B, Bartolomé Alvarez JM, Martínez-Cócera C. Urticaria caused by antihistamines: report of 5 cases. J Investig Allergol Clin Immunol 2009;19:317-20.

10. Lee SW, Byun JY, Choi YW, Myung KB, Choi HY. Fexofenadineinduced urticaria. Ann Dermatol 2011;23(Suppl 3):S329-32.

11. Schröter S, Damveld B, Marsch WC. Urticarial intolerance reaction to cetirizine. Clin Exp Dermatol 2002;27:185-7.

12. Tsunemi Y, Ihn H, Saeki H, Tamaki K. Cholinergic urticaria successfully treated with scopolamine butylbromide. Int J Dermatol 2003;42:850.

13. Ujiie H, Shimizu T, Natsuga K, Arita K, Tomizawa K, Shimizu H. Severe cholinergic urticaria successfully treated with scopolamine butylbromide in addition to antihistamines. Clin Exp Dermatol 2006;31:5889. 